\title{
Conceptualización y partes del cuerpo en quechua en el s. XVII
}

\section{Conceptualization and Parts of the Body in Quechua in the s. XVII}

\author{
Carlos Alberto Faucet Pareja \\ Universidad Nacional Mayor de San Marcos \\ carlos.faucet@unmsm.edu.pe
}

\begin{abstract}
Resumen
Este trabajo apunta a caracterizar tanto la manera en la que las partes del cuerpo eran conceptualizadas por los quechua hablantes de inicios del siglo XVII, como la conceptualización de las expresiones metafóricas/metonímicas en las que los nombres de las partes del cuerpo intervenían. El corpus analizado es de naturaleza textual y está conformado por el manuscrito de Huarochirí (1608) y las cartas de Cotahuasi (1616).
\end{abstract}

Palabras clave: Conceptualización; partes del cuerpo; semántica quechua; manuscrito de Huarochirí; cartas de Cotahuasi.

\begin{abstract}
In this paper I aim to describe the way body parts were conceptualized by early seventeenth century Quechua speakers, Also I intend to show the conceptualization of metaphoric and metonymic expressions in which body parts were involved. The corpus analyzed here is constituted by the Huarochirí manuscript(1608) and the Cotahuasi letters (1616), both of textual nature.
\end{abstract}

Keywords: Conceptualization; body parts; Quechua semantics; Huarochirí manuscript; Cotahuasi letters. 


\section{Carlos Alberto Faucet Pareja}

\section{Introducción}

Este trabajo se desarrolla con base en textos escritos en quechua a inicios del siglo XVII. Los objetivos son caracterizar la manera en la que las partes del cuerpo eran conceptualizadas por los quechua hablantes de aquel tiempo y caracterizar también la conceptualización de las expresiones metafóricas/metonímicas en las que los nombres de las partes del cuerpo intervenían. En lingüística cognitiva, el término conceptualización refiere a la construcción del significado realizada por el individuo mediante la activación de determinados dominios conceptuales a través de determinadas operaciones mentales (cf. van Hoek, 1999; Evans, 2007). De acuerdo con esto, el presente trabajo es, en principio, acerca de la semántica del quechua de la época, pero también acerca de la cognición de sus hablantes, tal como semántica y cognición quedaron cristalizadas en las expresiones que implicaban nombres de partes del cuerpo.

La teoría asumida es la de la metáfora y metonimia conceptual de Lakoff y Johnson (1998). En los estudios de lingüística andina que se apoyan en esta obra, el procedimiento común consiste en partir de las expresiones lingüísticas reales para justificar la postulación de las metáforas/metonimias conceptuales -las operaciones mentales - que convengan al caso, y sostener después que estas metáforas/metonimias conceptuales explican aquellas expresiones lingüísticas. Tal procedimiento circular es superado aquí con el apoyo de datos extralingüísticos de la época que respaldarían los procesos cognitivos postulados.

La estructura del trabajo es la siguiente: en la primera sección se describe la naturaleza de los textos analizados, se arguye en qué sentido pueden conformar un corpus coherente y merecedor de análisis, se detalla el instrumento con el que los datos fueron recogidos y el método con el que fueron analizados; en la segunda sección, se presenta los resultados del recojo; en la tercera sección se realiza una interpretación de los resultados en el marco de la teoría aludida y se compara y defiende esta interpretación en relación con la literatura previa; finalmente, en la última sección, se expone las conclusiones.

\section{Corpus y método}

El corpus está constituido por el manuscrito de Huarochirí (1608) y las cartas de Cotahuasi (1616). El primero, bastante conocido y de autor anónimo, es un documento que reúne diferentes prácticas y relatos de los habitantes de la región de Huarochirí (Lima) (Rostworowski, 1987). El segundo es un conjunto de cartas 
en las que Cristóbal Castillo, curaca de Cotahuasi (Arequipa), dirige una serie de exigencias a ciertas personas de un ayllu bajo su jurisdicción (Itier, 2005). Se considera aquí que estos materiales son equiparables y pueden constituir un corpus coherente $^{1}$ en tanto fueron producidos con menos de una década de diferencia por individuos evangelizados hablantes de quechua de la rama II (Torero, 2002; Adelaar, 1994), si acaso no de la misma variedad: el quechua general de la colonia (Itier, 2011). Aunque el tema de la conceptualización en quechua ha sido tocado, explícita o implícitamente, por Hurtado de Mendoza Santander (2001), Weber (2003), Garcés (2004), Godenzzi (2005) y Gálvez Astorayme (2013), ninguno ha analizado el quechua antiguo y ni la mitad de ellos se ha basado en textos, sino solo en palabras y frases aisladas. Además de estos vacíos en la literatura previa, la selección del corpus se justifica en el hecho de que este representa los primeros textos extensos de corte profano elaborados por hablantes/escribientes de quechua. Su análisis permitirá una comparación sistemática con corpus posteriores y un eventual seguimiento de la evolución de la semántica y cognición quechua.

Para el recojo de los datos, en primer lugar, se elaboró una lista de aproximadamente 60 nombres de partes del cuerpo en quechua sobre la base de todos los lexemas simples presentes en un estudio de quechua cuzqueño de Louise Stark (1969) — excluidos los hispanismos-, más un buen número de términos faltantes y formas de otras variedades de quechua II, tanto de fuentes actuales como antiguas. Luego, por cada miembro de esta lista se hizo una búsqueda en el corpus con la asistencia de las herramientas digitales del proyecto Langas (http://www. langas.cnrs.fr/\#/recherche_corpus).

Para la interpretación de los resultados así obtenidos se procedió primero con el análisis de los nombres de partes del cuerpo que aparecieran en expresiones denotativas - es decir, aquellas en las que el nombre refería efectivamente a una parte del cuerpo-; solo después, con el de los casos no denotativos. Finalmente, para la contrastación de las hipótesis que guiaron la interpretación se recurrió a evidencias extralingüísticas. Este punto, desarrollado y justificado en la subsección 3.4, constituye un aporte metodológico del presente trabajo.

1 La coherencia del conjunto es confirmada por el hecho de que en los dos materiales el dominio ŝunqu/sunqu 'corazón, vísceras en general' es el que participa más productivamente en la conceptualización de otros dominios. Sin embargo, no se deje de tener en cuenta la advertencia de la nota 3. 


\section{Carlos Alberto Faucet Pareja}

\section{Resultados}

Del total de la lista buscada, solo los 19 nombres de partes del cuerpo - o somatismos - de la tabla 1 fueron registrados en el corpus, ya en usos denotativos o en metafóricos/metonímicos (del 1 al 16). En cualquiera de estos, los somatismos registrados pueden aparecer, además de con los sufijos de genitivo - $p a$ y de acusativo $-k t a$, con morfemas de funciones y/o significados espaciales, como el locativo - $p i$ 'en', el ablativo -manta 'desde', el limitativo -kama 'hasta', el direccional -man 'a', la posposición sawa 'encima, fuera' o los sustantivos $u k u$ 'interior' y ćawpi 'centro'; y servir así como puntos de referencia para la localización espacial de otros entes y actividades; e igualmente, pueden recibir la anteposición de frases adjetivas y numerales. De los registros de ŝunqu/sunqu2, 22 de 35 son metafóricos/ metonímicos; de maki, 7 de 8; de ullu, 2 de 3; de uya, 6 de 7; de uma, 16 de 19; de tullu, 1 de 2; de rikra, 9 de 9; de ĉaki/čaki, 6 de 6; ; de ŝimi 4 de 4; de siki, 2 de 2; de ĉanka/čanka, 3 de 3 ; de $w a \hat{s} a, 2$ de 2; de čukča, 3 de 5; de ñawi, 5 de 8; de rinri, 1 de 3; de kunka, 1 de 1.

Tabla 1. Lista de los nombres de partes del cuerpo en quechua registrados en el corpus
I. ŝunqu/sunqu 'corazón,
5. uma 'cabeza' vísceras'
6. tullu 'hueso, esqueleto'
2. maki 'mano, brazo'
7. rikra 'brazo'
3. ullu 'pene'
8. çaki/čaki 'pie'
4. uya 'rostro'
9. ŝimi/simi 'boca'

2 El buscador de Langas arroja los datos del manuscrito en una forma fonológica conservadora -que sigue la hipótesis de Landerman (1982) en cuanto a la naturaleza de las sibilantes-y los de las cartas en forma grafémica. En el presente trabajo, para facilitar la comparación, la última ha sido volcada en una forma semejante a la del ayacuchano actual. La forma que corresponde al manuscrito es la que aparece a la izquierda de la barra.

3 De hecho, este lexema es el que presenta la mayor cantidad de ocurrencias metafóricas/metonímicas. Sin embargo, estas corresponden a un uso metalingüístico - que cubre el amplio rango de los vocablos castellanos palabra, narración, voz, mensaje, etc.- en el que el manuscrito de Huarochirí y las cartas de Cotahuasi no son comparables, puesto que el primero es una narración de narraciones, profusa en referencias intratextuales y discurso referido, mientras que las cartas no tienen esa naturaleza. Por eso, los usos metalingüísticos de simi/simi no han sido tenidos en cuenta aquí. 

IO. siki 'nalgas'
I5. rinri 'oreja'
II. çanka/čanka 'muslo'
I6. kunka 'cuello'
I2. waŝa/wasa 'espalda'
I7. ñati 'hígado'
I3. čukča 'cabello'
I8. sinqa 'nariz'
I4. ñawi 'ojo'
19. wiksa 'barriga, vientre'

\section{Discusión}

\subsection{Breve formulación del marco teórico}

Los resultados obtenidos en el presente trabajo son interpretados en el marco de la teoría de la metáfora y metonimia conceptual de Lakoff y Johnson (1998). Según esta, la metáfora es un fenómeno cognitivo que está en la base del sistema conceptual humano, por lo cual impregna y pauta el lenguaje, el pensamiento, la percepción y la acción (Lakoff y Johnson, 1998); fenómeno que consistiría, fundamentalmente, en la elaboración más o menos convencionalizada de algunos dominios conceptuales de acuerdo con la estructura de otros más básicos en la experiencia humana (Soriano, 2012). Según Johnson (1991), las experiencias más básicas corresponden a las interacciones del cuerpo humano con su entorno.

En el terreno lingüístico, las metáforas conceptuales se reflejarían y podrían ser estudiadas a partir de las expresiones metafóricas. Por ejemplo, la expresión Cuando terminó de exponer, todo el auditorio comenzó a bombardearlo con contraejemplos permitiría entrever que los castellanohablantes que entienden y profieren expresiones de ese tipo operarían cognitivamente activando el dominio conceptual discusión ${ }^{4}$ con el apoyo de la activación del dominio guerra; esto es, con la metáfora conceptual una discusión es una guerra. Como consecuencia, las personas que discuten serían pensadas y referidas como enemigos o rivales, sus argumentos como armas y/o estrategias, su mayor o menor éxito en convencer como una victoria o una derrota, etc.

4 Por convención, los dominios y las metáforas/metonimias conceptuales aparecen en versalitas, mientras que las expresiones metafóricas/metonímicas aparecen en altas y bajas. 
Carlos Alberto Faucet Pareja

Tabla 2. Algunas metáforas conceptuales y sus respectivas expresiones metafóricas

\begin{tabular}{l|l}
\hline $\begin{array}{l}\text { Metáforas } \\
\text { conceptuales }\end{array}$ & $\begin{array}{l}\text { Expresiones metafóricas (en } \\
\text { castellano peruano) }\end{array}$ \\
\hline $\begin{array}{l}\text { las ideas son } \\
\text { alimentos }\end{array}$ & $\begin{array}{l}\text { No puedo digerir tantos conceptos. } \\
\text { Parece que no procesó nada de lo } \\
\text { que le dijiste. } \\
\text { Sus ponencias son poco } \\
\text { sustanciosas. }\end{array}$ \\
\hline el amor es una \\
guerra & $\begin{array}{l}\text { Ahí viene el inconquistable. } \\
\text { Quedo desarmado cada vez que } \\
\text { me mira. } \\
\text { Luché mucho para que me quiera } \\
\text { aunque sea un poquito. }\end{array}$ \\
\hline arriba es bueno & $\begin{array}{l}\text { Realmente «te me caíste» al } \\
\text { comportarte así. } \\
\text { Su amor propio está en el subsuelo. } \\
\text { No descenderé al nivel de ese } \\
\text { sujeto. }\end{array}$ \\
\hline
\end{tabular}

En la teoría de Lakoff y Johnson (1998), la metonimia es concebida también como un fenómeno cognitivo con consecuencias lingüísticas y extralingüísticas sistemáticas. A diferencia de la metáfora, sin embargo, la metonimia no serviría para estructurar dominios, sino para activarlos; y no operaría entre dominios distantes_como efectivamente lo son discusión y guerra o ideas y alimentos_, sino entre dominios cercanos o subdominios (Cuenca y Hilferty, 1999; Barcelona, 2013).

Tabla 3. Algunas metonimias conceptuales y sus respectivas expresiones metonímicas

\begin{tabular}{l|l}
\hline $\begin{array}{l}\text { Metonimias } \\
\text { conceptuales }\end{array}$ & $\begin{array}{l}\text { Expresiones metonímicas (en } \\
\text { castellano peruano) }\end{array}$ \\
\hline la parte por el todo & $\begin{array}{l}\text { Ven a ayudar, aquí faltan manos. } \\
\text { (MANO por PERSONA) } \\
\text { Tengo cuatro bocas que } \\
\text { alimentar. } \\
\text { (BOCA por PERSONA) }\end{array}$ \\
\hline
\end{tabular}




\begin{tabular}{l|l}
\hline $\begin{array}{l}\text { Metonimias } \\
\text { conceptuales }\end{array}$ & $\begin{array}{l}\text { Expresiones metonímicas (en } \\
\text { castellano peruano) }\end{array}$ \\
\hline $\begin{array}{l}\text { el contenedor por el } \\
\text { contenido }\end{array}$ & $\begin{array}{l}\text { Entre los dos se metieron como } \\
\text { tres cajas. } \\
\text { (CAJA por BOTELLA, BOTELLA } \\
\text { por BEBIDA) } \\
\text { Un par de vasos y nada más. } \\
\text { (vASO por BEBIDA) }\end{array}$ \\
\hline & $\begin{array}{l}\text { Ni siquiera ha leído a Vallejo. } \\
\text { (VALLJO por LOS LIBROS } \\
\text { ESCRITOS POR VALLEJO) } \\
\text { Dice que tiene Un picasso } \\
\text { original. } \\
\text { (PICASSO por LOS CUADROS } \\
\text { PINTADOS POR PICASSO) }\end{array}$ \\
\hline
\end{tabular}

\subsection{Interpretación de los resultados}

Las expresiones alrededor de las partes del cuerpo registradas en el corpus revelarían la omnipresencia de dos tipos de metáforas conceptuales: X ES UN CONTENEDOR Y Y ES UNA PERSONA, donde las variables $\mathrm{x}$ y y corresponden a las partes del cuerpo humano y a entes no humanos, respectivamente. Las metáforas del primer tipo serían responsables de que los somatismos registrados puedan recibir morfemas y funciones espaciales incluso en los usos estrictamente denotativos - cuando refieren a partes del cuerpo humano-. Así, la metáfora LA CABEZA ${ }^{5}$ ES UN CONTENEDOR explicaría que en el corpus haya afirmaciones acerca de que hay cosas que pueden estar fuera o dentro de los límites de una cabeza humana ${ }^{6}$, como en los fragmentos de texto que siguen.

(1) «qamqa ancha kuyaŝqam kanki; llamaktapaŝ huchayuqpa llamantaraqmi mikupunki; qamta wañuchiŝpapaŝ hatun fiestapiraqmi

5 Los dominios y metáforas/metonimias conceptuales postulados serán enunciados en castellano.

6 Cuando la glosa ofrecida por el buscador de Langas sea suficiente para visualizar la metáfora, el fragmento pertinente será puesto en cursivas; cuando no sea así, se ofrecerá una traducción literal del mismo. Dicho sea de paso, el buscador de Langas arroja los datos sin referencia a folio o página alguna, de modo que los ejemplos ofrecidos aquí aparecen de tal manera, no así las citas. 
umansawa ĉuraŝpa takichiŝunki; chaymanta watanpi qamta lluqsîichiŝpari huk llamanta nakaŝparaqmi takichiŝunki» ñiŝpa ñirqan "Serás muy querido», le prometió Cuniraya, «y las llamas, sobre todo las llamas del hombre culpable, te las comerás tú; y si alguien te mata, primero te hará bailar en una gran fiesta, poniéndote sobre su cabeza y, después, todos los años te sacará y, sacrificándote una llama, te hará bailar»'

(2) Chayŝi chay wamanqa «qayllataraqmi rin; ñaĉqam tarinki» ñiptinŝi «qamqa ancha kuŝiyuqmi kanki; mikuŝpapaŝ ñawpaqraqmi qintikta almorzakunki, chaymantari piŝqukunakta; wañuchiŝpari qamta wañuchiq runam huk llamanwan waqachiŝunki; hinaŝpari takiŝpapaŝ umanpim ĉuraŝunki chaypi Sumaŝpa tiyanqaykipaq» [ñiŝpa ñirqan] 'Cuando el halcón le aseguró que Cahuillaca andaba todavía muy cerca y que ya casi estaba por alcanzarla, Cuniraya le prometió: «Tendrás mucha suerte y, cuando comas, primero almorzarás picaflores y después otros pájaros; el hombre que te mate, hará que se llore tu muerte, sacrificándote una llama, y bailará, poniéndote sobre su cabeza para que resplandezcas allí». Lit.: En su cabeza.

Obsérvese que las metáforas del tipo x es un contenedor — donde el contenedor se configura como un espacio de límites definidos con relación a los cuales las cosas pueden estar dentro/fuera (Johnson, 1991, p. 98) - predicen la aparición de expresiones acerca de que las partes del cuerpo tienen un contenido o de que es posible/imposible recibir nuevos o más contenidos en ellas. Los registros ofrecidos en las siguientes subsecciones (3.2.1 en adelante) respaldan contundentemente esta predicción.

Por su parte, las metáforas conceptuales del segundo tipo — de aplicación bastante más general- serían responsables de que los volúmenes de los cerros y rocas, al igual que los cuerpos de animales, divinidades y criaturas fantásticas, sean interpretados en términos humanos a lo largo de todo el corpus; es decir, en los términos de las divisiones y nombres de partes del cuerpo humano. Así, las metáforas conceptuales las cosas/los accidentes geográficos son personas explican que en el corpus haya afirmaciones acerca de que ciertos entes no humanos tienen, literalmente, boca.

7 En esta edición, sin embargo, container es traducido como receptáculo.

$36 \quad$ Lengua \& Sociedad 
(3) Chayŝi chay Pariacacaqa chayta rikuŝpa chay huchuylla quêanta yaqullanwan chay quĉap siminta kirpaykupurqan 'Cuando Pariacaca vio esto, cubrió con su manta la bocatoma del pequeño estanque [de donde Chuquisuso sacaba el agua para regar]'. Lit.: La boca de la cocha.

(4) Kay Cocochalla ñiŝqa rarqap siminpim kanan rumi chirawaŝqa tiyan chay Chuquisuso ñiŝqa warmi 'Sabemos que la mujer llamada Chuquisuso aún se encuentra, petrificada, en la bocatoma de esta acequia de Cocochalla'. Lit.: La boca de la acequia.

(5) Paykuna uramanta hamuqkunam aŝlla aychata paykunap puyñunpa siminsawa ĉrapuq karqan 'Los que llegaban de abajo colocaban una pequeña cantidad de carne sobre la boca de sus cántaros'.

Estos dos tipos de metáforas conceptuales interactúan constantemente en el corpus y son responsables de la mayor cantidad de expresiones no denotativas. No obstante, en las siguientes subsecciones solo se presentará los registros en los que las metáforas del tipo $\mathrm{x}$ es un contenedor interactúan con metonimias y metáforas diferentes de y es una persona. Es decir, se mostrará los registros en los cuales la conceptualización de las partes del cuerpo humano interviene, a su vez, en la conceptualización de dominios no referidos al cuerpo de alguna entidad, sino de dominios de otra naturaleza, como los sentimientos, las ideas, el poder, las medidas longitudinales, etc. Los nombres 1-7 de la tabla 1 son los que evidencian estos usos.

\subsubsection{Dominio ŜUNQU/SUNQU 'corazón, vísceras en general'}

La metáfora conceptual el corazón es un contenedor explica un buen número de afirmaciones presentes en el corpus acerca de que el corazón tiene un contenido, que se puede recibir nuevos contenidos en él y que en su interior pueden suceder actividades. Dicha metáfora determina también que lo que pueda estar contenido en el corazón - pensamientos, sentimientos, etc.— sea conceptualizado, a su vez, mediante metáforas como las ideas/sentimientos son cosas.

(6) Dios qapaq, sunquyta piñakuyniyuqta kamawanchik, honrayuqta 'El señor Dios ha hecho nuestro genio provisto $\mathrm{d}[\mathrm{el}$ sentimiento $\mathrm{d}] \mathrm{e}$ la cólera y d[el sentido d]el honor'. Lit.: Un corazón con enojo y honra. 
(7) «kunan tutam virgen Santa María mamanchikpaq yanapayninwan atiparqumuni; amataq kananmantaqa pillapaŝ chay wasiman yaykunchikchu; yaykuqta ćayaqta rikuŝpaqa padremanpaŝ willaymanmi; porque alli yaĉaykuy ñiŝqayta tukuy ŝunquykipitaq ĉaskikuychik» ñiŝpâ̂ tukuy runakunakta willarqan " La noche pasada con la ayuda de nuestra madre, la Virgen Santa María, conseguí vencerlo. A partir de hoy, ique nadie de ustedes entre en esa casa! Si viera a alguien entrar o acercarse, se lo diría al padre. Reciban con todo su corazón las buenas noticias que les he contado». Fue así como habló a toda la gente.' Lit.: Reciban en todo el corazón los buenos conocimientos que he contado.

(8) Chayŝi kayhina chika sumaqta rikuŝpa tuylla ŝunqunpi «kaytaqmi warmiy kanqa» ñispa yuyakurqan. 'Al verla tan hermosa, pensó enseguida en su corazón que era ella quien sería su mujer'.

(9) Chayŝi payqa «allim» ñiŝpaŝ ŝunqunpiqa ancha piñaŝpa yaykurqan 'Finalmente dijo «Está bien» y, con su corazón lleno de rabia, entró'. Lit.: Muy enojado en el corazón.

(10) Manam wiñaychu sunquypi piñakuy takyanmanchu 'La cólera no ha de asentarse por siempre en mi corazón'.

(11) Dios qapaqri «runamasiykita kikiykitahina kuyakuy, munakuy» ñispa sunqunchikpi takyachisun 'Y el Señor Dios dice: «quiere y ama a tu prójimo como a ti mismo»', asentemos firmemente [estas palabras] en nuestros corazones.

Por otra parte, el hecho de que el corazón sea conceptualizado como un contenedor explica que su contenido pueda ser calificado indirectamente mediante la metonimia el contenedor por el contenido.

(12) Mana huk runa diosman chiqa ŝunqu kutiriŝpa kaykunakta «supaymi» ñiŝpa ñiptinqa ichapaŝ unayraq chayhina kawsanman karqan 'Si un hombre no hubiese vuelto a Dios con un corazón sincero, diciéndoles que estos eran demonios, es posible que hubieran seguido con estas costumbres durante mucho tiempo todavía'. Lit.: Corazón verdadero. 
(13) Mana allin sunquwan «allin» niqqa ima mana allimanpas urmaykuqni kasqa 'El que decía «sí» con mala intención caía en todo tipo de males'. Lit.: Con corazón malo.

La metonimia el contenedor por el contenido explica también que una petición de no acatar las órdenes con dos corazones equivalga a sostener que no se las acate con hipocresía, con contenidos diferentes en el corazón.

(14) Yariraqchu kunan cristiano pachanpi ima uenturaywantaqcha Diospa munayñinpi, Diospa kalpanwan kamachiykichik: ama iskay sunqu kay kamachisqayta huñiwankichu 'Cuanto más ahora, en tiempo de los cristianos, con qué ventura mía, por la voluntad de Dios, con el poder que me da Dios les ordeno: no acaten mis órdenes con doble intención'. Lit.: No [con] dos corazones.

La interacción de las metáforas conceptuales la actividad psicológica es actividad física, el corazón es un contenedor y las ideas son cosas con la metonimia el contenedor por el contenido explica que una afirmación acerca de aplastar el corazón sea interpretada en el sentido de apaciguar o reprimir los sentimientos contenidos en él.

(15) Kunankama upallan karqani, sunquyta ñitirqani 'Hasta ahora he callado y he sido paciente'. Lit.: He apretado mi corazón.

Igualmente, las metáforas el corazón es un contenedor y el corazón es una piedra explican en conjunto que afirmaciones literales acerca de que el corazón es una piedra tengan sentido: si el corazón es de piedra, sus límites son duros y resultan impenetrables para nuevas ideas o sentimientos que permitan a su poseedor recapacitar.

(16) Apuyki kani, manam pipas qichuwanmanchu. Dios qapaq yayallanchikmi. Yačakuy, manchakuy. Ama rumi sunqu kasunchu 'Soy tu señor y nadie me puede quitar [este señorío]. Solo Dios Nuestro Señor y Padre. Que lo sepas y temas. No seamos empedernidos'. Lit.: Compréndelo y témelo. No seamos corazones pétreos. 
(17) Rumi sunqukta imanasqaykim qamkunapaq munayniykillanta infiernoman astayta munaspa, awqahina mana Diosta manĉâ̂pa [...] ¿Qué puedo hacer contra unos corazones empedernidos, que por su propia voluntad quieren ir al infierno y viven como traidores, sin temor de Dios [...]?'. Lit.: ¿Qué puedo hacérselo, corazones pétreos [...]?

La interacción de las metáforas grande es malo y el corazón es un contenedor explica que afirmaciones acerca de que un corazón es grande sean interpretadas en un sentido negativo ${ }^{8}$.

(18) Ancha hatun sunquñam tukuyta munankichik 'Se han puesto indómitos y lo quieren todo'. Lit.: [Sus] corazones [son] bien grandes ya, ustedes lo quieren todo.

(19) Ama hijo mio hatun sunquqa 'Hijo mío, no seas rebelde'. Lit.: Corazón grande.

\subsubsection{Dominio MAKI 'mano'}

La interacción de una metonimia conceptual del tipo LA PARTE POR EL TODO (MANO POR PERSONA) con las metáforas LA MANO ES UN CONTENEDOR Y CONTENER ES TENER PODER explica que afirmaciones literales acerca de que una persona se encuentra en manos de otra transmitan la idea de que la primera está de facto bajo el poder o la jurisdicción de la segunda.

(20) Kayhina mana imallawanpaŝ qiŝspinanta unanchaŝpaŝ ña ĉawpi tutaktapaŝ yalliptin supayqa hinataq humpichiq kaptin mamanchik Santa Maríakta waqyarqan ñiŝpa: «[...] qam sapay quyallaytaqmi kay peligromanta qiŝpichiwanki; wawayki Jesúsniyta willapullawaytaq kanallanqa kay huchaymanta qiŝpichiwachuntaq kay mana alli supaypa makinmanta» 'Como creía que no iba a salvarse de ninguna manera, puesto que ya había pasado la media noche y el demonio continuaba persiguiéndolo sin darle tregua, clamó a nuestra madre Santa María, diciéndole: «[...] Tú, que eres mi única reina, sálvame de este peligro;

8 En contraste con la interpretación de grande (hatun) en el contexto de pene ( $u l l u)$, por ejemplo, donde la cualidad es considerada positiva: «Kay Rucanacuto ŝutiyuqtaŝ runakunapaŝ huchuylla ulluyuq kaŝpaqa «hatun kanqa» ñiŝpa mañaq karqanku [...] Los hombres que tenían un pene pequeño le pedían a Rucanacoto que se los agrandara» (Taylor, 1987, pp. 196-197). 
Conceptualización y partes del cuerpo en quechua en el s. XVII

intercede con tu hijo, mi Jesús, para que me salve de las manos de este demonio malo»'. Lit.: Que me libere de las manos de este demonio malo.

(21) Hermano mío, yanqa alcansasqapas kachun provision ñuqap makiymantaqa mañankichu? Nuqa apuyki kani. Diospa quyñinpi, munay[ñi] pi makiypitaqmi kanki. Diospaq kawsayta quwasqankama. Ñuqa wañuptiypas churiypas makinpitaqmi kanki Diospa munaŝqankama. Diostaq munasqa kachun. Trigollaypaq kamachiŝqanki «riy» ñispa. Manam hamunchu. Diosrayku kachun. Ichas haykaptaq makiyman urmaykunqa 'Hermano mío ¿has pedido que quede sin efecto la provisión que ha sido alcanzada y los deja bajo mi poder? Yo soy tu señor. Si Dios los concede, seguirás bajo mi voluntad y en mi poder mientras Dios me preste vida. Y cuando me muera estarás en poder de mi hijo, mientras Dios quiera. Alabado sea Dios. Había encargado a alguien para que venga a trabajar mi trigo. No ha venido. [Que venga] en nombre de Dios. Tal vez en algún momento caiga entre mis manos'. Lit.: De mi mano [...] estarás en mi voluntad, en mi mano [...] en la mano de mi hijo [...] a mi mano caerá.

En (20) y (21), el hecho de que las manos sean conceptualizadas como contenedores explica que alguien pueda caer en ellas (urmaku-) o ser liberado de ellas (qiŝpichi-).

\subsubsection{Dominio Ullu 'pene'}

Una metonimia del tipo EL ÓRGANO POR LA FUNCIÓN (PENE POR COITO) explica que una afirmación literal acerca de que alguien puede morir por causa de un pene signifique que esa persona puede morir ${ }^{9}$ por haber tenido relaciones sexuales con un hombre.

(22) Chayŝi payri hinataq willarqan «huk warmim - hatun apu willkap churinmi-ullumanta ñaĉqa wañun» ñiŝpa 'Entonces, el otro le contestó

9 En el ejemplo (22), el uso de wañu- 'morir' es literal, no metafórico; lo confirma la presencia del verbo alliya- 'mejorarse, restablecerse' en el contexto inmediato: «(Kay ŝimin kanan ancha achka chay warmi alliyaŝqankama; chaytaqa qipanpiraqmi qillqaŝun; kananri ñawpaqman kutiŝun) [...] (Este cuento, hasta el restablecimiento de la mujer, es muy largo. Lo transcribiremos después. Ahora vamos a volver al relato anterior)» (Taylor, 1987, pp. 92-93). 
a su vez: «Hay una mujer —la hija de ese gran señor- que, por causa de un pene, casi se muere».

\subsubsection{Dominio UYA 'rostro'}

Las metáforas conceptuales EL ROSTRO ES UN CONTENEDOR, LAS IDEAS SON COSAS Y LA REALIDAD ES INTERIORIDAD ${ }^{10}$ explican en conjunto que en el corpus pueda haber afirmaciones acerca de que una característica abstracta - el ser cristianopueda, literalmente, estar contenida en algo concreto y visible como un rostro y que, por ser así, aquella característica es falsa.

(23) Ama uyallanchikpi, sumaynillanchikpi cristiano tukuykachasunchu. Obranchikpi Xpohina rurasun, caridadniyuq kasun 'No seamos cristianos sólo en figura y apariencia. Actuemos como Cristo en nuestras obras y seamos caritativos'. Lit.: Solo en nuestro rostro.

\subsubsection{Dominio uma 'cabeza'}

La metáfora conceptual un colectivo es un cuerpo explica que una afirmación acerca de que alguien es la cabeza transmita la idea de que dicha persona es el jefe, quien dirige el colectivo.

(24) Chika agrauiosta rikuchiwanki chayqa, manachu apuyki kaspa umayki kaspa piñakuy kanqa? Rumichu kani? 'Con todas las ofensas que me has hecho, ¿cómo no va a haber cólera en quien es tu señor y jefe? ¿Acaso soy una piedra? (= un insensible?)'. Lit.: ¿ [...] Siendo tu señor, siendo tu cabeza?"11

\subsubsection{Dominio TUllu 'hueso'}

Una metonimia del tipo LA PARTE POR EL TODO (HUESO POR CADÁVER) y otra del tipo El RESULTADO POR EL PROCESO (CADÁVER POR MATAR) explican que una

10 Obsérvese que esta metáfora conceptual es complementaria con el análisis del dominio del corazón: puesto que el corazón está en el interior, su contenido - malo o bueno- es, en principio, real; de ahí que en numerosas expresiones registradas se insista en que hablar y pensar desde/con el corazón es hablar con sinceridad.

11 El análisis de umayki kaspa, lit.: 'siendo tu cabeza', como 'siendo tu jefe' queda confirmado por la presencia de la frase morfosintácticamente gemela y pseudosinónima apuyki kaspa 'siendo tu señor'. 
advertencia literal acerca de que los huesos del interlocutor puedan ir a dar a una laguna funcione como una convincente amenaza de asesinato.

(25) Chayŝi chaykunaqa manataq munarqanchu "wañuchuntaq» ñiŝpa. Chayŝi chay Llacsamisa ñiŝqanchikqa piñariŝpa «wawqi, ñam chika mita ñiyki; paqtaĉ tulluykipâs quĉa ñiqman rinman; ñuqam 'kawsachun' ñini» ñiŝpaŝ ñirqan 'Pero sus hermanos no quisieron en absoluto dejarlo vivir. «QQue muera!», dijeron. Entonces Llacsamisa se enojó. «Hermanos», les dijo, «ya tantas veces les he reiterado mi voluntad. ¡Cuidado que sus ${ }^{12}$ huesos vayan a acabar en la laguna! Yo quiero que viva».

\subsubsection{Dominio RIKRA 'brazo'}

La metáfora conceptual EL BRAZO ES UNA MEDIDA explica que en el corpus pueda haber una afirmación literal acerca de que algo tiene siete brazos y medio.

(26) Huk chupa ñiŝqa ichukta pirtaŝpaŝ ancha qirukunakta caqnaŝpa chayman pillwiq karqan iŝkayta. Kaymi suninman qancis rikra chiqtayuq. Chaymantam hatunninmanmi iŝkay brazo alli makallanchikhina 'Pintaban (?) una variedad de ichu llamada chupa para que representase a seres humanos y, después de haber atado una gran cantidad de palos, colocaban en cima las dos imágenes que habían fabricado. Éstas tenían siete brazos y medio de alto y fácilmente, dos brazos de ancho'.

4.3. De los alrededor de 60 nombres de partes del cuerpo léxicamente disponibles para el quechuahablante del siglo XVII, solo 19 - excluidos los hispanismosfueron registrados en el corpus en usos denotativos y/o metafóricos/metonímicos. De esos 19, los primeros 16 aparecieron en los usos del último tipo. De estas 16, solo las 7 primeras (tabla 1) participan en la conceptualización de dominios más abstractos, no referidos a volúmenes o cuerpos de otros entes. De esas, 5 pertenecen a la mitad superior del cuerpo humano, una de las principales formas en las que todavía hoy el cuerpo es dividido en el mundo quechua (Classen, 1990).

Algunas de las metáforas/metonimias conceptuales postuladas aquí son bastante intuitivas y ya han sido aducidas, de una u otra manera, en la bibliografía de lingüística quechua de corte cognitivo, pero todas lo han sido en alguna familia lingüística (cf. Cuenca y Hilferty, 1999; Soriano, 2012), por lo que

12 Este sus marca posesión de segunda persona, no de tercera. 


\section{Carlos Alberto Faucet Pareja}

no constituyen recursos ad hoc en este trabajo, sino constructos por lo menos parcialmente validados en otras latitudes. Entre el conjunto de las metáforas/ metonimias conceptuales postuladas, las del tipo $\mathrm{x}$ es un contenedor y y es una persona, junto con las metonimias del tipo la parte por el todo, se han mostrado como las más productivas y las que mejor describirían los procesos cognitivos del quechuahablante del siglo XVII, por lo menos en relación con las expresiones hechas alrededor de las partes del cuerpo.

Entre la literatura previa, los trabajos que se centran en las partes del cuerpo en quechua antiguo son de corte filológico, pero coinciden en analizar ŝunqu/sunqu como una sede o un recipiente (cf. Golte, 1973, p. 214; Taylor, 2000, pp. 27, nota 26). Contrastado con trabajos sobre partes del cuerpo en quechua actual e inscritos en la línea de la metáfora y metonimia conceptual, el presente análisis coincide con el de Hurtado de Mendoza Santander para el quechua cuzqueño (2001) y con el de Garcés para quechua boliviano (2004); pero se separa del de Gálvez Astorayme para el quechua ayacuchano (2013). Esta autora no analiza las partes del cuerpo como contenedores y sostiene lo siguiente acerca de la locución sunqupi hatallay, lit. en corazón guardar [atesorar], interpretable como 'extrañar a alguien':

[m]etonímicamente, el corazón es referido como el sentimiento por el cual se extraña a alguien; y metafóricamente, el sentimiento es referido en términos de un objeto, el cual puede guardarse. (2013, p. 21)

En primer lugar, se considera aquí que la presencia del verbo hatalli- 'guardar' y del locativo - $p i$ 'en' sufijado a sunqu en los datos de Gálvez Astorayme exige nítidamente el análisis de sunqu como contenedor, a la manera del presente trabajo. En segundo lugar, puesto que la metonimia consiste en la referencia indirecta a un dominio conceptual mediante otro dominio estrechamente vinculado, empírica o experiencialmente cercano, no se entiende de qué manera el corazón —objetivamente, una parte del cuerpo- podría referir metonímicamente, sin más, a alguna noción abstracta como lo es un sentimiento o una idea. Gálvez Astorayme, por tanto, no habría trabajado correctamente con sus datos ni con la teoría.

4.4. En los estudios de lingüística cognitiva sobre metáfora/metonimia se ha vuelto común la siguiente práctica: partir de las expresiones lingüísticas reales para justificar la postulación de las metáforas/metonimias conceptuales -las operaciones mentales- que convengan al caso, y sostener después que estas metáforas/metonimias conceptuales explican aquellas expresiones lingüísticas (cf. los antecedentes enlistados en la sección 1, con la excepción de Weber, 2003). Este modo de proceder es evidentemente circular y está especialmente injustificado 
en un marco de espíritu integral como el de la lingüística cognitiva, la cual, al rechazar las operaciones exclusivamente lingüísticas, permite la predicción de consecuencias no lingüísticas por cada uno de sus constructos. Considérese en este sentido lo señalado por Lakoff y Johnson (1998) a propósito de la metáfora conceptual una discusión es una guerra:

Es importante ver que no es que nos limitemos a hablar de discusiones en términos bélicos. Podemos, realmente, ganar o perder las discusiones. Vemos a la persona con la que discutimos como un oponente. Atacamos sus posiciones y defendemos las nuestras. Planeamos y usamos estrategias [...]. Muchas de las cosas que hacemos al discutir están estructuradas parcialmente por el concepto de guerra [...]. En este sentido, la metáfora una discusión es una guerra es algo de lo que vivimos en nuestra cultura, estructura las acciones que ejecutamos al discutir.

Tratemos de imaginar una cultura en la que las discusiones no se vieran en términos bélicos [...]. Imaginemos una cultura en la que una discusión fuera visualizada como una danza, los participantes como bailarines, y en la cual el fin fuera ejecutarla de una manera equilibrada y estéticamente agradable. En esta cultura, la gente consideraría las discusiones de una manera diferente, las experimentaría de una manera distinta, las llevaría a cabo de otro modo y hablaría de ellas de otra manera. Pero nosotros seguramente no consideraríamos que estaban discutiendo en absoluto [...].

[...] El concepto se estructura metafóricamente, la actividad se estructura metafóricamente, y, en consecuencia, el lenguaje se estructura metafóricamente. (1998, pp. 40-42)

De acuerdo con el texto citado, las metáforas conceptuales no solo tendrían reflejos lingüísticos, sino también conductuales y culturales, tanto a escala individual como social. En otras palabras, toda metáfora conceptual postulada a partir del registro lingüístico debería hallar confirmación en algún tipo de registro no lingüístico; y de no ser así, tendría que ser descartada o calificada de insuficientemente justificada ${ }^{13}$.

En la línea así señalada, las metáforas conceptuales del tipo y es una persona parecen suficientemente justificadas por la evidencia etnográfica andina. Por su parte, las metáforas conceptuales del tipo x es un contenedor - que están en la base de todo el análisis del presente trabajo- encuentran su reflejo extralingüístico en la práctica andina de la adivinación y predicción de acontecimientos a partir

13 Por préstamo, calco o arcaísmo, una determinada lengua puede cobijar expresiones metafóricas que no reflejen ninguna metáfora conceptual productiva en la misma. 
de la observación de las entrañas animales. En el manuscrito de Huarochirí, la práctica quedó plasmada en el siguiente fragmento.

Chayŝi chay kimsaĉunkamanta huqin llakwaŝ Quita Pariasca ŝutiyuq runaqa, may pacham chay kimsaĉunka runakuna ñatinta ŝunquntallamapmanta rikurqan, chay pacha ñiŝpa ñirqan: «a atac, manam allichu pacha, wawqi; qipanpiqa kay Pariacaca yayanchik purumanqataqmi» ñiŝpaŝ rimarqan [...] Chayŝi hukninqa «say, Quita Pariasca, imamantam qam unanchanki; kay ŝunqunpiqa ancha alliktam Pariacaca yayanchik riman» ñiŝpa ñiptinŝi payqa manâ̂ ŝunqunta rikuypaqpaŝ qayllaykurqanchu.

Cuando los treinta hombres estaban mirando el hígado y el corazón de la llama, uno de ellos, un llacuas llamado Quita Pariasca, dijo: «iAy de nosotros! La suerte no es buena, hermanos. En el futuro nuestro padre Pariacaca será abandonado» [...] Uno de los presentes le dijo: «Oye Quita Pariasca, ¿cómo justificas tu interpretación? Nuestro padre Pariacaca nos está señalando cosas muy buenas en este corazón». Al oír estas palabras, Quita Pariasca ni siquiera se acercó a examinar el corazón. (Taylor, 1987, pp. 277-278)

Si el corazón y el hígado no hubiesen sido conceptualizados como contenedores, la actividad de buscar en ellos los mensajes divinos no habría tenido sentido. Aunque el fragmento corresponde a la reproducción de un relato heredado y no a la descripción de una escena atestiguada por el narrador, el método de adivinación mediante la observación de las partes del cuerpo de animales no estaba en desuso en el siglo XVII ni se restringía a las entrañas de las llamas; en 1621, el padre Joseph de Arriaga, extirpador de idolatrías asignado a la arquidiócesis de Lima, a la cual siempre ha pertenecido el territorio de Huarochirí, acusaba el sacrificio de cuyes, práctica para la cual había un encargado oficial, quien «abriéndoles con la vña adivina por ellos, mirando de qué parte sale sangre, o qué parte se menea de las entrañas» (Arriaga, 1621, p. 25). Sin embargo, este método de adivinación tampoco se restringía al cuerpo de los animales; el padre Arriaga acusaba también la adivinación a partir de las carnosidades de los brazos de los interesados: «si se le menea el derecho dize q' sucederá bien y si el izquierdo que mal» (Arriaga, 1621, p. 36).

Por todo lo anterior, las metáforas conceptuales del tipo x es un contenedor hallan respaldo en la evidencia extralingüística y habrían sido procesos cognitivos reales del quechuahablante del siglo xvir. 


\section{Conclusiones}

Las siguientes son las conclusiones alcanzadas en el presente trabajo:

1. En la cognición del quechuahablante del siglo XviI, las partes del cuerpo humano habrían sido conceptualizadas de acuerdo con metáforas del tipo $\mathrm{x}$ es un contenedor, las cuales determinaban, a su vez, el léxico y la morfosintaxis de las construcciones en las que los nombres de dichas partes aparecían.

2. Las partes del cuerpo humano, asimismo, habrían servido para la conceptualización de los cuerpos y volúmenes de entes no humanos, de acuerdo con metáforas del tipo y es una persona.

3. Las metáforas $\mathrm{x}$ es un contenedor y y es una persona, junto con las metonimias del tipo la parte por el todo, habrían sido los procesos más productivos en la cognición del quechuahablante del siglo XVII, por lo menos con relación a las partes del cuerpo.

4. Las partes del cuerpo humano habrían servido para la conceptualización de dominios más abstractos, como el de los sentimientos, las ideas, el poder, las medidas longitudinales, el coito, el asesinato, el liderazgo, etc.

5. Las partes correspondientes a la mitad superior del cuerpo humano habrían sido las más productivas en relación con la conceptualización de dominios más abstractos.

6. Las partes del cuerpo habrían determinado no solo las piezas léxicas de las construcciones en las que aparecían, sino incluso su interpretación: hatun 'grande' era interpretado como una cualidad buena o mala dependiendo de la parte del cuerpo a la cual acompañara.

7. Las metáforas conceptuales del tipo $\mathrm{x}$ es un contenedor, postuladas aquí $\mathrm{y}$ respaldadas por la evidencia extralingüística, habrían sido procesos cognitivos reales del quechuahablante de inicios del siglo XVII, mediante los cuales no solo habría creado significado y se habría expresado, sino también pensado y actuado. 


\section{Referencias bibliográficas}

Adelaar, W. (1994). La procedencia dialectal del manuscrito de Huarochirí en base a sus características lingüísticas. Revista Andina, 12(1), 137-54.

Arriaga, J. de. (1621). La extirpación de la idolatría en el Perú. http://www.biblioteca.org.ar/libros/155230.pdf

Barcelona, A. (2012). La metonimia conceptual. En Iraide Ibarretxe-Antuñano y Javier Valenzuela (Dirs.), Lingüística cognitiva (pp. 123-146). Barcelona: Anthropos.

Classen, C. (1990). Inca cosmology and the human body (Tesis doctoral no publicada). McGill University, Montreal.

Cuenca, J., y Hilferty, M. J. (1999). Introducción a la lingüistica cognitiva. Barcelona: Ariel.

Evans, V. (2007). A glossary of cognitive linguistics. Edinburgo: Edinburgh University Press.

Gálvez Astorayme, I. (2013). Unidades fraseológicas del cuerpo humano en el quechua ayacuchano. Escritura y pensamiento, 16(33), 7-24.

Garcés, F. (2004). El cuerpo como discurso y los discursos sobre el cuerpo: la metaforicidad en el quechua boliviano. Punto Cero, 9(9), 64-70.

Godenzzi, J. (2005). En las redes del lenguaje. Cognición, discurso y sociedad en los Andes. Lima: Centro de Investigación de la Universidad del Pacífico / Colegio de las Américas / Asociación Universitaria Interamericana.

Golte, J. (1973). El concepto del sonqo en el runa simi del siglo XVI. Indiana, 1, 213-218.

Itier, C. (2005). Las cartas en quechua de Cotahuasi: el pensamiento político de un cacique de inicios del siglo XVII. En Bernard Lavellé (Ed.), Máscaras, tretas y rodeos del discurso colonial en los Andes (pp. 43-73). Lima: Instituto Francés de Estudios Andinos, Instituto Riva-Agüero.

Itier, C. (2011). What was the lengua general of Colonial Peru? En Adrian Pearce y Paul Heggarty (Eds.), History and Linguistics in the Andes (pp. 63-85). Londres: Institute for the Study of the Americas - Palgrave.

Johnson, M. (1991). El cuerpo en la mente. Fundamentos corporales del significado, la imaginación y la razón. Madrid: Debate.

Lakoff, G., y Johnson, M. (1998). Metáforas de la vida cotidiana. Barcelona: Cátedra. 
Landerman, P. (1982). Las sibilantes castellanas, quechuas y aimaras en el siglo Xvi: un enigma tridimensional. En Rodolfo Cerrón-Palomino (Ed.), Aula quechua (pp. 203-234). Lima: Signo.

Rostworowski, M. (1987). Presentación. En Gerald Taylor, Ritos y tradiciones de Huarochirí. Manuscrito quechua de comienzos del siglo XVII (pp. 9-11). Lima: Instituto de Estudios Peruanos, Instituto Francés de Estudios Andinos.

Soriano, C. (2012). La metáfora conceptual. En Iraide Ibarretxe-Antuñano y Javier Valenzuela (Dirs.), Lingüística cognitiva (pp. 97-121). Barcelona: Anthropos.

Stark, L. (1969). The lexical structure of Quechua body parts. Anthropological Linguistics, 11(1), 1-15.

Taylor, G. (1987). Ritos y tradiciones de Huarochirí. Manuscrito quechua de comienzos del siglo XVII. Lima: Instituto de Estudios Peruanos / Institut Français d'Études Andines.

Taylor, G. (2000). Supay. In Taylor, Gerald: Camac, camay y camasca y otros ensayos sobre Huarochirí y Yauyos (pp. 19-34). Lima: Institut Français d'Études Andines / Centro de Estudios Regionales Andinos «Centro Bartolomé de Las Casas».

Torero, A. (2002). Idiomas de los Andes. Lingüística e Historia. Lima: Institut Français d'Études Andines, Horizonte.

Van Hoek, K. (1999). Cognitive linguistics. En Robert Wilson y Frank Keil (Eds.), The MIT encyclopedia of the cognitive sciences (pp. 134-135). Massachusetts: The MIT Press.

Weber, D. (2003). When the Jacaranda flowers: parascientific cause-effect relations in Huallaga (Huánuco) Quechua. En Mary Ruth Wise, Thomas Headland y Ruth Brend (Eds.), Language and life: essays in memory of Kenneth L. Pike (pp. 217-246). Dallas: sIL International and University of Texas at Arlington. 